\title{
Chapter 14 \\ Uses Genres and Media Ensembles: \\ A Conceptual Roadmap for Research of Convergent Audiences
}

\author{
Jakub Macek
}

\subsection{Introduction}

It is more than obvious: Television audiences have changed. We can see it in our homes. We can observe it in how we watch films and TV shows. It is evidenced in the ways we decide about, get and recirculate content. What is the difference? Simply said: multiplication and convergence. Multiplication and convergence of technological objects (and textual interfaces and platforms) coming hand-in-hand with multiplication and convergence in our TV practices as was already noted more than a decade ago by Jenkins (2006). The other chapters in this section outline it very well-as members of convergent audiences, we still watch broadcasting, but we also download and stream, we search for online content across state boundaries and we share the content with others and some of us even remix and recreate existing content. Moreover, at home we use multiple screens, and our preferences over their sizes and qualities are linked with specific content preferences and with specific situations, as we have seen in the chapter about young Flemish audiences.

For the field of audience research, this change has created a profound challenge, as it has further complicated the always troublesome notion of watching television. One of the crucial questions - how to assess conceptually and methodologically TV audiences' agency so our research provides satisfyingly valid and useful outcomes? has become even more important than ever before as the story is not just about watching and television but also about many other related practices and about other technological objects.

Audience research was quite surprisingly unprepared for the new situation, although the change was well foreseen (cf. Jenkins 2006; Lotz 2007). Even when households had already started the intensive domestication of multipurpose media

\footnotetext{
J. Macek $(\bowtie)$

Faculty of Social Studies, Masaryk University, Jostova 10, 60200 Brno, Czech Republic

e-mail: jmacek@fss.muni.cz 
such as wired computers, and media scholars became interested in the new phenomena, the research — when dealing with everyday audiences and their practicesmostly focused just on one particular type of practice linked usually with a particular type of text and a particular object. The reasons for that were obviously pragmatic. In the "traditional TV situation," any practice was more or less firmly connected to a single media technology, and so we did not have a strong urge to look analytically at dynamics between objects, content and practices. An imperative to approach the "media home" as a complex of interrelated phenomena was evident, for example, in British domestication research, but even this holistic tradition mainly focused-with some exceptions, as Haddon (2006) remarked - on particular media such as TV and later mobile phone or the networked PC. And related proposals of double articulated research taking the media into account both as texts and objects were considered too complicated for data collection and analysis (Livingstone 2007).

Of course, the media in everyday life were, in terms of objects and texts, always multiplied. In the good old television home there was always something more than the TV set: Radios and tape recorders, hi-fis, books, journals and newspapers, landlines, later the VCR, video games and microcomputers. But as the colorful realm of domestic viewership has encountered digitalization and dematerialization of content, the relation between texts, objects and practices has become fluid. Or, in Henry Jenkins' words, convergent: content freed from its dependence on a certain proprietary object can be and is distributed and consumed across diverse channels and interfaces (cf. Jenkins 2006). In the case of TV, broadcasting flow has eventually lost its mighty monopoly.

The change that has come along with the proliferation and domestication of networked digital media (namely mobile devices and wired computers) has underlined the importance of a few simple facts. Firstly, with content being consumed across multiple diverse screens and devices we can no longer rely on the until-recently stable and taken-for-granted relation between texts, objects and practices. Secondly, particular media, texts and practices do not stand alone in our everyday life: They are neither isolated phenomena nor discrete entities, but are inevitably interrelated and integrated in the order of our everyday routines. People treat their media-related practices and domesticated media objects as reflexively constructed and changeable systems - with classificatory rules, with inscribed values and needs and with a personal history of decisions, replacements and acquisitions. And thirdly, the multiplication of practices linked with watching TV content emphasizes that being an audience member refers to multiple distinct situations filled with different types of content, used objects and co-viewers.

In our research on post-TV audiences, we focus specifically on the problem of the complexity and permanently shifting nature of the media-related practices of current Czech audiences - one of our main aims at Masaryk University is to frame and understand audiences' practices as a dynamic complex firmly embedded in everyday life. Empirically we build upon qualitative and quantitative audience research conducted in several waves since 2012 (Macek et al. 2015; Macek 2015, 2017; Macek and Zahrádka 2016); however, in this chapter I focus not on the results themselves (as they have already been published) but on the explication of two crucial conceptual 
constructs we employ in our inquiries. These two concepts-uses genres, originally formulated by Bakardjieva (Bakardjieva 2005; Bakardjieva and Smith 2001), and media ensembles, originating from our own work (Macek 2015)—enable us to assess content-related practices while taking into an account the three aforementioned simple facts: as typified and interrelated forms of agency organized at the individual level in a more or less reflexively created system referring to socially and culturally conditioned needs and motivations of the audience members. Consequently, these two concepts provide us with the opportunity to draw an analytically comprehensible and satisfying picture of current TV and post-TV audiences-a picture that also enables us to address and outline the specificities of current small-market audiences.

\subsection{Uses Genres}

Calgary-based media scholar Maria Bakardjieva introduced her notion of uses genres in order to assess ordinary Internet users' online practices embedded in the fabric of everyday life (Bakardjieva 2005; Bakardjieva and Smith 2001). Inspired by Voloshinov's approach to language and Bakhtin's concept of speech genres, Bakardjieva proposes uses genres as both typified and situated uses of technology-according to her, we use technologies in typical, stabilized ways, and we use them in typical situational settings that refer to the immediate contexts of our everyday lives as well as to the broader social, cultural, economic and political order. The notion of uses genres inevitably resembles Berger and Luckmann's (1991 [1967]) concept of institutionalized routines-i.e., routines drawing on intersubjective agreement on "how things should be done properly." Both conceptions acknowledge that we learn what and how to do something from others and that the "proper doing" is individually variable while it is, to some degree, also normative. But, in contrast to the classics of social constructivism, Bakardjieva focuses explicitly and specifically on the uses of technological objects and their positions in everyday life and thus offers a more suitable conceptual solution for audience research.

In her approach, Bakardjieva proficiently avoids the dark risks of technological determinism as well as sweeping voluntarism. As she notes, relations between technology uses and their situational frameworks are inevitably mutual and dialectical. On the one hand, uses genres are formed by structures of everyday life because "typical social-biographical situations in which subjects find themselves give rise to specific 'little behaviour genres', including genres of technology use" (Bakardjieva and Smith 2001: 68). On the other hand, Bakardjieva sees users as active agents of technological, social and cultural processes; by using technologies, users inevitably reshape situations. And so they eventually do even with the technologies they employ: "Positing users as doers, and not simply as consumers, interpreters, adopters and so on, makes it logical to go on looking for the effects of their action on the tools they select, appropriate and implement" (Bakardjieva 2005: 34).

The concept of uses genres proved itself quite useful in Maria Bakardjieva's ethnographic study of Internet users: It enabled her to draw a complex picture of 
North American users adopting and routinizing the new technology in the late 1990s and early 2000s and as such, her study represents one of the best available inquiries conducted within the tradition of critically oriented domestication research. Thanks to her conceptual work, Bakardjieva was able to analyze and reconstruct the studied practices in relation to the underlying needs of the participants and, therefore, to systematize and interpret the seemingly borderless realm of online practices.

Although the concept of uses genres has not been widely used in audience research, we have decided to employ it in our research on Czech convergent and traditional TV audiences because we have found it applicable to watching television content. In our case, i.e., in the case of media audiences, uses genres are represented by typified and situated uses of audiovisual media both as texts and as material (technological) objects. To put it simply, the concept of uses genres gives us a chance to explicitly address the fact that we watch TV content in multiple and yet typical ways, at typical times and in typical places and with the typical company of our close others, and that regularities of these "typicalities" are presumably shared by viewers with similar status, needs, cultural taste, etc. In other words, the concept helps us to find the explicit analytical sensibility necessary for grasping that "watching television" includes not only a certain agency (selection, reception or recirculation of content, and handling technological objects), certain content (films, TV series, documents) and certain objects (TV set, mobile phone, laptop, etc.) but also certain actors ("just me," "me and my partner," "with kids," etc.) and spatiotemporal coordinates (e.g., "home in the evening," "every morning during breakfast in the kitchen," or "afternoon when travelling from school"). Here, of course, comes the situated nature of uses genresthe answers for the simple questions of "with whom," "where" and "when" describe the basis of an observed situation.

And last but not least, each distinct uses genre can and should be seen as replying to diverse motivations and as satisfying specific and variable needs. As we argue in our study of pirating audiovisual content, needs linked with watching TV content are of two types:

[C]hoices of particular media made by audiences are informed by what might be called textual motivations (related to "purely textual" preferences of particular genres, narrative structures etc.) as well as by contextual motivations [...], such as those related to respondents' everyday lives (available time, need for activities shared within couples, cultural capital forming the recipient's identity and taste). (Macek and Zahrádka 2016: 341-342)

What are the typical or prevailing uses genres we can observe in relation to watching TV content? An illustrative case of a couple of our interviewees-let's call them Diana and Robert - might be helpful. Robert, in his late $30 \mathrm{~s}$, and Diana, almost 30, have lived together for about a year. They have a TV antenna and broadband Internet connection at home and they subscribe to Netflix. Robert is a frequent and passionate consumer of TV series, Diana is rather a modest viewer; while he watches multiple TV series and on several occasions during his day, she usually watches only two or three times a week when they spend their time together in the evening. Their shared watching represents one of the most common uses genre-prime-time watching. In their case, it occurs in their living room, in the "main evening time," and 
it is usually linked with the consumption of what they consider premium contentnew episodes of preferred TV series (such as Game of Thrones or The Young Pope) or, less frequently, new or well-rated movies. They do this together because they want to spend "uncomplicated private time together," as they describe it, and also because it comes with the possibility of sharing the experience and talking about it. They say that they mostly do not have any problem agreeing on what to watch; however, Diana does not understand English very well and thus she needs Czech subtitles or dubbing. So, when Netflix offers a movie or series of their choice only with English subtitles (and this happens quite often since a large part of its catalogue is not localized for Czech audiences), Robert downloads the film and subtitles from online sites.

Besides prime-time, Diana and Robert sometimes spend together binge-watching for more or less a whole Saturday or Sunday, i.e., watching many episodes in a row or watching even a whole season of a particular show. Diana admits that it is mainly Robert's call but she accepts it as a form of "total relaxation." As in the case of prime-time watching, Diana and Robert prefer to watch premium content on this occasion but in contrast to it they watch also in bed using his or her laptop.

Robert alone watches series on Netflix while having breakfast and then usually during his lunch break-he works two or three days per week from home and so he has an opportunity to do it this way. For breakfast, he usually prefers some 2025 minutes-long formats ("something lighter," in his words), for his lunch break "something more regular" with 50 minutes-long episodes. For this type of watching, he chooses content that Diana would not watch with him because it does not fit her taste.

Diana rarely watches alone-when Robert is not at home, she turns on the TV just to have it as a background for other activities and to fill the silence. Or she watches "some older stuff," such as Friends or Gilmore Girls, which she has downloaded in dubbed versions to her laptop. When watching these, Diana does not need to fully focus, since she knows the episodes already, but listening to Czech dubbing enables her to be on Facebook and on Instagram at the same time or even do some preparation for her job.

Together they go to the cinema every two or three months - for a movie "that is worth seeing on a large screen." Sometimes just the two of them, sometimes with other couples, but they always consider it a special event linked with dinner or some drinks and socializing afterward.

As we can see in this illustrative example, Diana and Robert are typical post-TV viewers employing the TV set and laptops for their viewing habits and combining several sources of content. Importantly, their uses genres vary in many aspects, from needs they fulfill through consumed content to situational settings. Illustratively, we can draw a line between their shared and individual uses genres and conclude that the shared genres help Diana and Robert to maintain shared privacy and to negotiate their shared tastes. But even the shared uses genres (in the case of this couple's prime-time watching, binge-watching and cinema-going) are obviously distinct regarding some of their basic parameters, which indicates that these genres play different roles in their everyday personal routines. 


\subsection{Media Ensembles}

In the case of Diana and Robert, we can also clearly see another crucial aspect of contemporary habits of viewing TV content: Uses genres are organized into systems. Each particular uses genre stands among other uses genres, and its role is defined by its position in relation to them. Visiting the cinema is positioned in contrast to ordinary everyday watching, individual genres in contrast to shared genres, and/or focused watching in contrast to watching as an ancillary part of other, and more central activities. Moreover, all these practices stand amidst a wider, more general set of media-related uses genres that include, for example, news reception, reading books and journals, using social media for online and mobile interactions, and so on. Inevitably, any valid empirical inquiry of uses genres-and of current media audiences in general—requires acknowledging this fact.

For this purpose, we work with the concept of media ensembles (Macek 2015). This concept, unlike the similar and widely used notion of media repertoires (e.g., Ferguson and Perse 1993; Hasebrink and Popp 2006; Kim 2016), does not put at its center the media technologies or content channels used by a social actor but instead focuses at the same time on media practices, technologies and content, i.e., on uses genres: Media ensembles are dynamic, time-varying classificatory systems that "can be characterized as individually specific sets of practices, media objects and texts-individually specific to the extent as any socially and culturally conditioned dispositives" (Macek 2015: 47).

Like the uses genres that constitute them, particular media ensembles are changeable over time. They have their histories of choices, of domestication and abandoning particular technologies, and of substituting older uses genres with new ones. But they are more than just "packages of media and related doings"-as classificatory systems, media ensembles refer to the order of one's everyday life, to its rules. They play their role in its constitution; they are one of the key classificatory axes of one's everyday world since they are usually reflexively constructed in relation both to individual needs and domestic negotiations regarding the moral economies of our households. In a completely different context-in relation to political practices-Mouffe (2005) wrote about classificatory systems and orders:

Things could always be otherwise and therefore every order is predicated on the exclusion of other possibilities.[...] What is at a given moment considered as the "natural" order - jointly with the "common sense" which accompanies it - is the result of sedimented practices; it is never the manifestation of a deeper objectivity exterior to the practices that bring it into being. To summarize this point: every order is political and based on some form of exclusion. (Mouffe 2005: 18)

Indeed, this applies also to media ensembles. They result from the perpetual struggle over what is considered among household members as reasonably acceptable, likable and preferred in a cultural, economic, political and status-related sense. Moreover, media ensembles are political in both (private and public) meanings: They are gendered, and they stem from power relations within households, relationships and families. At the same time, media ensembles, as one of the interfaces between 
private and public, embody and manifest the wider, contextual power relations affecting the private sphere as well as the eventual participatory ambitions of the private individuals toward public spaces.

What in particular does the concept of media ensembles contribute to our understanding of TV watching and post-TV audiences? At the individual level, the concept pushes us to see uses genres as organized and interconnected-it explicitly draws our analytical attention to the fact that some objects and texts are employed across two or more distinct uses genres and that some uses genres rely on more than one technology or content type. Moreover, the concept enables us to systematically assess the extent and intensity of individual reception practices-and to put them in the context of other media-related practices. In the case of our illustrative couple, we can see two individual media ensembles partly overlapping at the level of shared uses genres but diverging in the extent of individual genres. Moreover, a closer look at Diana's media ensemble would reveal that she spends-unlike Robert-her leisure time reading fiction and multiple magazine titles which can be seen as the functional equivalent to Robert's breakfast/lunch viewing habits. And last but not least, each of their media ensembles is significantly shaped by Diana's reluctance to subscribe not only to Netflix but also to HBO Go; instead, she renewed her yearly subscription to Respekt (a Czech political weekly). Robert accepted her argument that it is a more sensible and mature choice than a subscription to another, "redundant" VOD service. In this decision, their moral economy reflecting and articulating their negotiation about shared values was manifested - and through that, the symbolic classificatory power of their intertwined media ensembles.

Media ensembles, however, are useful not only at the micro-social level as a conceptual tool for understanding and analyzing everyday media uses of one particular couple. At a population level, the concept offers the possibility to cluster audience members in line with similarities in their media ensembles-regarding their structure (in terms of involved uses genres), intensity of content reception, manifested content preferences, importance of watching films and TV series, etc. In other words, media ensembles offer a key to a more nuanced segmentation of TV audiences better suitable for the convergent, post-TV situation.

\subsection{Researching the Uses Genres and Media Ensembles of Current Post-TV Audiences}

The effort at the identification of typical uses genres based on empirical evidence, the reconstruction of prevailing media ensembles, and the assessment of their distribution among general audiences encounters one principal obstacle-both genres and ensembles change in time, and sometimes, as new technology or new services enter the market, they may transform quite swiftly. And this, at first sight, complicates any attempt to formulate a stable set of measuring tools that would be firmly and surely valid across time and across various cross-cut studies. 
For example, since 2016 in Czechia we have observed this kind of transformation with Netflix, HBO GO and Apple TV+ opening their platforms in the country. Before 2016, the convergent segment of Czech TV audiences-making up one-third of Czech TV viewers (cf. Macek 2017; Macek and Zahrádka 2016)—relied mainly upon downloading content from unofficial online sources (mainly from download servers such as Uloz.to) and using shady streaming services (e.g., SerialyCZ.cz). After 2016, some uses genres - those newly including official VOD services-have been rearticulated into the audiences' practices, while some old practices have finally more or less disappeared since 2014 (such as those linked with visiting DVD rentals). Along with that, smart TVs enabling full online connectivity and VOD services' applications have definitely cornered the market. As a result, the valid formulation of particular measures and indicators for audience surveys necessarily differed in 2019 from the measures and indicators we used in December 2014 (Macek et al. 2015).

There are two interrelated methodological solutions enabling us to deal with this permanent flux. Firstly, there is no better tool to sketch sensitively current audience activities than qualitative inquiry - it helps to thoroughly understand the communication partners and to study them and their practices in the complex setting of their everyday lives. With a large enough sample, it also enables one to draw a preliminary map of the most common uses genres and typical media ensembles and connect them with particular needs and motivations (which is later very helpful in the interpretation of survey data). To continue with the above-mentioned example, from April 2018 to June 2019 we interviewed 80 members of Czech convergent audiences (41 women and 39 men aged 18-58, with an average age of 31 years) aiming to reconstruct their viewing habits and related practices and the interviewees' motivations for them (Jansová et al. 2019). The findings from this inquiry served to reformulate our questionnaire originally used in 2014 and to include or reword items indicating shifts in particular practices and uses and preferences of technological objects, so that the questionnaire would better fit the current situation.

Secondly, the concepts of uses genres and media ensembles implicate four dimensions of inquiry that should serve as the main grid structuring the general logic of both qualitative study and quantitative surveys. And precisely these dimensions-simply composed of what, how, with whom and when people watch-play the role of kinds of meta-tools ensuring the comparability and validity of data across different data collections.

- The content dimension focuses on what types of content (films, TV series or particular content genres) participants watch, how important they consider them and how often they watch them.

- The technological dimension refers to the technologies employed in watching and aims to identify the structure and the degree of participants' convergence, i.e., what screens, content sources and other technological artifacts are used in particular uses genres.

- The social dimension refers to questions regarding with whom participants watch certain content and what content they watch alone, with whom they talk about 
the content they watch and how they receive information about what is worth viewing.

- The spatiotemporal dimension includes questions on when and where participants watch their content.

While in qualitative inquiry these dimensions may remain rather implicit (as they do not necessarily directly form the structure of an interview), in a quantitative questionnaire they directly affect formulations of items as well as the data outcome. For a 2019 survey (the results were not yet available for this book) conducted on the general Czech 18+ population, key items were formulated as follows:

- "How often do you watch films? How often do you watch TV series?" // Answer: 5-point Likert scale ranging from "Never" to "Several times a day".

- "How much do you agree or disagree with the following statements?": "I wouldn't mind at all if I can't watch films [TV series]." // Answer: 5-point Likert scale ranging from "Absolutely disagree" to "Totally agree".

- "You've said that you watch films [TV series]. What technology or technologies do you use for watching them?" // Multiple choice: "TV - via broadcasting", "TV - but with apps like Netflix, HBO GO... or from DVD, USB, other connected media or from connected PC", "PC monitor", "Laptop or tablet", "Projector", "Mobile phone" etc.

- "You've said that you watch films [TV series]. With whom do you watch them at least once a month?" // Answers: "Alone", "With my partner", "With my kids", "With my parents", "With my friends" etc.

- "You've said that you watch films [TV series] alone [with you partner] [with your kids] [...]. When do you usually watch like that?" // Multiple choice: "While eating or after that", "In the evening as part of the main evening time", "In other free time I have", "As a background when I do other things", "When travelling", "At work or in a school" etc.

- "When you watch films [TV series] alone [with you partner] [with your kids] [...], what technology do you use most often for such watching?" // Single-choice answers: "TV - via broadcasting", "TV - but with apps like Netflix and HBO GO, or from DVD, USB, other connected media or from connected PC", "PC monitor", "Laptop or tablet", "Projector", "Mobile phone" etc.

- "How do you get access to the films or TV series you watch?" // Multiple choice: "I buy them on DVD or other media", "I borrow them from friends on DVD or other media", "I download them from the Internet", "Someone else downloads them for me", "I watch them online for free", "I watch them on prepaid services like Netflix or HBO GO", "I buy them or rent them online (using iTunes, Google Play or similar services".

After filtering out questions irrelevant for a particular participant (e.g., participants watching films less than once per month are not considered film viewers and so they skip questions assessing films), each respondent provides in this concrete questionnaire an adequately detailed matrix of her or his uses genres and, therefore, of his or her media ensemble. Using clustering procedures, respondents are then 
organized into clusters drawing upon the structural similarity of their media ensembles or particular uses genres. And yes, the resulting pile of data might look a bit messy as it includes multiple variables in various mutual configurations. But in the end, it provides quite clear answers about the distribution of convergent uses genres and media ensembles in the Czech population (along with a lot of analytical joy).

\subsection{Specifics of Small-Market Audiences?}

The above-outlined research solution is, in its general logic, applicable to any convergent audience. Yet, two important topics remain untouched here: the topic of the specifics of small-market audiences and the topic of audiences' power (or capabilities) to resist contextual pressures embodied in strategies of official content distributors as well as in legislation. These two intertwined issues make the final point of this chapter-namely, they suggest that being a viewer in a small-and peripheral-market subordinated to global strategies comes with tactics of media consumption that very well reveal and emphasize the distinct characteristics of such a market.

As John Fiske-inspired by Michel de Certeau's critical notion of everyday life (de Certeau 1984)_remarked, popular culture is inherently a culture of resistance where the members of an audience aim to gain as much as possible for themselves from the quite little offered to them by strategic players, i.e., by content producers and distributors (Fiske 2010). People treat the commodity they receive-the contentnot necessarily in line with producers' expectations or intentions but in accordance with their own cultural and other needs. They may reject it; they may interpret it subversively; they may even reconfigure or remix it. Or they may not. But in any case, if they appropriate it, they do so within the context of their everyday life, embedding it in their own meanings and rituals. As a result, through appropriation they turn commodities into their own symbolic culture-into objects of popular culture. Henry Jenkins, Fiske's disciple, further notices that in a convergent situation, this gentle resistance gains more fuel because major content producers and distributors lose their until-recently more or less total control over distribution channels, and audiences at the same time gain a broader reservoir of resistance practices and more control over their consumption (Jenkins 2006). Importantly, this cultural resistance practiced through the appropriation of cultural commodities is often not explicitly political in terms of targeting power (a system, capitalism or patriarchal dominance and oppression). Instead, in most cases this resistance is a rather utilitarian act motivated by a need to obtain a better or more befitting experience, and it often takes the form of finding alternative ways of getting and providing access to content and its interpretation and reception-alternative in relation to the intentions of the strategic players (Macek and Zahrádka 2016).

In our previous research regarding content piracy in the Czech Republic (Macek and Zahrádka 2016) and in a more recent study of the motivations of Czech convergent audiences for paying for audiovisual content (Jansová et al. 2019), we have 
identified several uses genres that can be understood as specific to small-market audiences. Symptomatically, all of them can be read as acts of resistance and as audience members' attempts to get more effective control over their viewership.

As we already remarked in the introduction to this book, small- and peripheralmarket audiences often face situations in which they are not very well servedthey are not always offered content they actually want, the most current content or content properly customized for them in terms of language localization. Small- and peripheral-markets are simply not that economically enticing for global players and so they can be neglected, omitted, left out. We see it in Diana's example: She struggled to understand English spoken movies and TV series but her VOD service did not provide most of the content with Czech subtitles. The solution for that was simpleDiana and her partner downloaded the content they wanted from an alternative online source and they found subtitles for it on a community-based server offering subtitles translated and uploaded by other users. "After all, with the subscription to the service, we have already paid for the movie," said Diana, "so it's not my fault that I have to go elsewhere to get it [...] in Czech."

Downloading as a routine part of domestic watching of films and TV series in this case constitutes uses genres that bridge obstacles still typical for the Czech market with online audiovisual services-and in line with Diana's words, it is conceived by Czech viewers as a rather non-problematic solution (cf. Jansová et al. 2019). Another common tactic is streaming films and TV shows from non-authorized online platforms, and although many of these online sources were shut down in autumn 2019 in response to lawsuits filed by major content providers (and so at the time of writing this chapter it remains unclear whether this will lead to the end of non-authorized streaming in general), many participants still tend to consider downloading as one of the best solutions for alternative access to content hardly available by other means. Why? Because they do not see any other reasonable option, or they do not see any other option at all.

Of course, downloading and streaming content from alternative sources is not unique for the Czech or other small-market audiences. However, the Czech audiences are specific in their motivations for these activities: One of the key motivations for downloading and streaming is, along with the unsurprising intention to avoid paying, the above-illustrated need to access content which is not legally offered in the small market at all, or which is offered online without appropriate qualities (e.g., not including Czech translation, lacking localized additional information), or which is available only in domestic broadcasting. In other words, downloading and streaming have to be considered as an answer by the neglected to the neglecting.

This is further emphasized by the activities of Czech fan/media subcultures. Since the early 2000s, the most active audience members organized themselves into multiple interrelated knowledge communities that have developed their own grassroots strategies to substitute for the absence of an actual active presence of strong strategic actors in the online market for audiovisual content. They create their own translated subtitles for films and series, and they share them with other viewers through specialized Web sites (such as Titulky.com) or through general download servers. Or they directly create localized versions of audiovisual files with Czech subtitles 
embedded in the picture and, again, share them online via download services (e.g., Uloz.to). Moreover, responding to the lack of domestic information resources on current film and series productions, they have initiated a number of community projects (eventually even professionalized projects, such as Edna) systematically aggregating information about new titles and news from the entertainment industry. And although all that is practiced by a very small portion of the most engaged viewers, it has shaped the viewing habits of the majority of Czech convergent audiences, because they enabled the ordinary audience members to be actually convergent and to watch current international film and TV productions despite the apparent lack of interest of official content distributors to make it available for them.

\subsection{Conclusion}

Small-market audiences are as fluid and changeable as any other audience-and as are the major international and local content distributors' strategies and the trends in technological development. With Netflix, HBO Go and other VOD providers finally focusing on systematic localization of content, even the Czech convergent audiences will probably soon shift from downloading and streaming from non-authorized sources and the picture of their specifics drawing on data from current research will become obsolete. Nevertheless, more important for this chapter than to draw a temporal map of the specifics of particular small-market audiences is to suggest an applicable conceptual framework enabling us to assess basically any convergent audience-and, at the same time, to grasp empirically any potential specifics that might emerge across various types of current or future audiences.

The concepts of uses genres and media ensembles can play this role. As an alternative to the currently dominant notion of media repertoires, these two conceptual tools come with an explicit and intrinsic sensibility for the fact that media-related practices are structured both by the contexts of everyday life, and by broader contexts represented in cases of small-market audiences by the global market actors and their (dis)interests. This, along with their primary focus on situated practices instead of on technological tools, provides the concepts of uses genres and media ensemble with the ability to follow the ongoing changes in audience behavior not only with an emphasis on what is new but also with necessary respect to continuity of the analyzed agency - continuity in audience members' needs and motivations, in the role of watching audiovisual content in the structuring of everyday lives, and in audiences' aims to turn commodities into a vivid popular culture.

Acknowledgements This study was supported by the Technology Agency of the Czech Republic project "Research on the Impact of Current Legislation and the European Commission's Strategy for Digital Single Market on Czech Audiovisual Industry: Evaluation of the Copyright System and Preparation of Cultural Politics within the DSM" (No. TL01000306). 


\section{References}

Bakardjieva, M. (2005). Internet society: The internet in everyday life. London: Sage.

Bakardjieva, M., \& Smith, R. (2001). The internet in everyday life: Computer networking from the standpoint of the domestic user. New Media \& Society, 3(1), 67-83.

Berger, P. L., \& Luckmann, T. (1991). The social construction of reality: A treatise in the sociology of knowledge. London: Penguin.

de Certeau, M. (1984). The practice of everyday life. Berkeley: University of California Press.

Ferguson, D. A., \& Perse, E. M. (1993). Media and audience influences on channel repertoire. Journal of Broadcasting \& Electronic Media, 37(1), 31-47.

Fiske, J. (2010). Understanding popular culture. London: Routledge.

Haddon, L. (2006). Empirical studies using the domestication framework. In T. Berker, M. Hartmann, Y. Punie, \& K. J. Ward (Eds.), Domestication of media and technology (pp. 103-122). Maidenhead: Open University Press.

Hasebrink, U., \& Popp, J. (2006). Media repertoires as a result of selective media use: A conceptual approach to the analysis of patterns of exposure. Communications, 31(3), 369-387.

Jansová, I., Macek, J., Macková, A., \& Žádník, Š. (2019). Analýza podmínek pohybu českých spotřebiteli mezi zdroji s legálně a nelegálně šrireným audiovizuálním obsahem. Brno: Masaryk University.

Jenkins, H. (2006). Convergence culture: Where old and new media collide. New York: New York University Press.

Kim, S. J. (2016). A repertoire approach to cross-platform media use behavior. New Media \& Society, 18(3), 353-372.

Livingstone, S. (2007). On the material and the symbolic: Silverstone's double articulation of research traditions in new media studies. New Media \& Society, 9(1), 16-24.

Lotz, A. (2007). The television will be revolutionized. New York: NYU Press.

Macek, J. (2015). Média v pohybu: K proměně současných českých publik. Brno: Masaryk University.

Macek, J. (2017). Traditional and convergent domestic audiences: Towards a typology of the transforming Czech viewership of films and TV series. Iluminace, 29(2), 7-24.

Macek, J., Macková, A., Škařupová, K., \& Císařová, L. W. (2015). Old and new media in everyday life of the Czech audiences. Brno: Masaryk University.

Macek, J., \& Zahrádka, P. (2016). Online piracy and the transformation of the audiences' practices: The case of the Czech republic. In D. H. Hick \& R. Schmücker (Eds.), The aesthetics and ethics of copying (pp. 335-358). London: Bloomsbury.

Mouffe, C. (2005). On the political. London: Routledge.

Jakub Macek is Associate Professor of media studies, Masaryk University, Brno, Czech Republic. His research interests include the roles of new media in the transformation of current audiences and in political and civic participation. He was previously a member of VITOVIN, an interdisciplinary research project on the Internet and new users (2012-2015). Recently, he led the postdoctoral research project "New and Old Media in Everyday Life: Media Audiences at the Time of Transforming Media Uses" (2013-2015) and worked as a researcher at CATCH-EyoU, a Horizon 2020 project (2015-2018). 
Open Access This chapter is licensed under the terms of the Creative Commons Attribution 4.0 International License (http://creativecommons.org/licenses/by/4.0/), which permits use, sharing, adaptation, distribution and reproduction in any medium or format, as long as you give appropriate credit to the original author(s) and the source, provide a link to the Creative Commons license and indicate if changes were made.

The images or other third party material in this chapter are included in the chapter's Creative Commons license, unless indicated otherwise in a credit line to the material. If material is not included in the chapter's Creative Commons license and your intended use is not permitted by statutory regulation or exceeds the permitted use, you will need to obtain permission directly from the copyright holder.

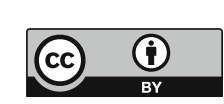

